\title{
Ishak versus METAVIR: Terminology, Convertibility and Correlation with Laboratory Changes in Chronic Hepatitis C
}

\author{
Gamal Shiha and Khaled Zalata \\ Internal medicine department $\mathcal{E}$ pathology department, Mansoura faculty of medicine
}

Egypt

\section{Introduction}

Ishak (modified Knodell score) and METAVIR scores are the most widely accepted scoring systems for assessment of fibrosis and necroinflammation in dealing with chronic hepatitis C. In METAVIR, only interface hepatitis and lobular necrosis determine the grade of activity, while in Ishak, portal infiltrate and confluent necrosis are included with the two previous parameters. Confluent necrosis is very rare in chronic hepatitis $C$, that in most patients the actual score limit is 12 instead of 18 (Ishak score), that mostly underscore the actual necroinflammation. Also, portal inflammatory infiltrate may reflect immunological response rather than necroinflammation. This may explain the discrepancy between enzyme elevation and necroinflammatory score as determined by Ishak score (modified HAI) in assessment of chronic hepatitis $C$ biopsy specimens. On the other hand, no study has clearly tested such discrepancy in applying METAVIR.

Some of the terminologies applied in METAVIR are in need of revision or declaration. For example; the term "septa" is used to mean actual fibrous bridges, while in Ishak score both terms; septa and bridges; are applied by different meaning. Ishak et al, 1995, in their system, applied both terminologies (septa \& bridges), however in completely different meaning. Septa, means expansion of portal tract edges without formation of bridges or actual connection between portal areas or portal area and central vein (1). On the other hand, the term bridge was applied to actual fibrous connection between two portal areas or portal area and central vein. Because of this confusion, some studies comparing both scoring systems have committed some mistakes.

Some studies have compared both Ishak and METAVIR systems, but they included small number of patients or included hepatitis B and hepatitis C. Therefore, the objectives of this chapter are:

- $\quad$ Revision of histological grading and staging in chronic hepatitis C.

- Clarification of the METAVIR terminology for future applications.

- Establishing an Ishak to METAVIR fibrosis score conversion table.

\section{Histological grading and staging in chronic hepatitis $C$}

The new approach to classify chronic hepatitis $C$ involves three separate considerations. The first is a comment on etiology. Frequently, this cannot be determined on the basis of 
histological appearance alone, and the diagnosis is made on the basis of other laboratory investigations. The second assessment relates to the severity and distribution of necroinflammatory activity (histological "grade"). Thirdly, an attempt should be made to assess the degree of fibrosis (histological "stage") (2).

\section{Patterns of necroinflammatory activity}

Inflammatory activity in the liver can be divided into two main components. The first involves portal tracts (portal hepatitis) with variable extension into the adjacent periportal regions (periportal hepatitis). The second involves liver parenchyma (lobular hepatitis). These different patterns of inflammation are probably related to the different pathways whereby circulating inflammatory cells can gain access to the liver (3).

\subsection{Portal / periportal hepatitis}

Inflammatory cells migrating across the endothelium of portal vessels pass into portal connective tissue which is rich in antigen presenting dendritic cells. A predominantly portal inflammatory infiltrate is one of the characteristic histological features of chronic hepatitis. However it should kept in mind that portal hepatitis by itself does not necessarily indicate a diagnosis of chronic hepatitis. Mild portal inflammatory changes, indistinguishable from low-grade chronic viral hepatitis, can be seen in a variety of conditions including systemic illness, nearby space-occupying lesion and even in some livers, which otherwise would be considered as normal. Furthermore, a predominantly portal inflammatory infiltrate is sometimes present in cases of acute viral hepatitis, without any implication of chronicity (4). Considerable attention has focused on the extension of portal inflammatory cells into the adjacent liver parenchyma associated with destruction of the limiting plate and damage to periportal hepatocytes (interface hepatitis) (5).

\subsection{Lobular hepatitis}

Inflammatory cells migrating across the endothelium of hepatic sinusoids can gain direct access to the liver parenchyma causing lobular inflammation. Typically this presents as "spotty" inflammation dispersed randomly throughout the liver parenchyma. In some cases inflammatory changes are more pronounced in perivenular (acinar zone 3) region and are associated with areas of confluent necrosis. When areas of zone 3 necrosis link vascular structures, in particular portal tracts to hepatic venules, the term "bridging necrosis" is used. Rarely in severe cases, there may be complete destruction of hepatocytes in one or more acini (panacinar necrosis or multiacinar necrosis) (6).

\subsection{Functional significance of necroinflammatory activity}

The main purpose in identifying different patterns of necroinflammatory activity is that these may have different functional and prognostic significance in terms of progression to fibrosis and ultimately cirrhosis.

Interface hepatitis has long been considered as an important lesion in the evolution of chronic hepatitis to cirrhosis. In the original classification proposed by De Groote et al, 1968 (7), chronic persistent hepatitis (portal inflammation without piecemeal necrosis) was thought to have a favorable prognosis, whereas chronic active hepatitis (portal inflammation with piecemeal necrosis) was regarded as having substantial risk for progression to cirrhosis. Interface hepatitis with associated periportal liver cell loss and collapse of the 
reticulin framework can readily be visualized as a mechanism for the development of periportal fibrosis (2).

There have been few attempts to validate this lesion as a prognostic feature in serial biopsies. One study showed that the presence of interface hepatitis in initial biopsies from patients with chronic hepatitis correlate with subsequent development of cirrhosis (8). Two other studies have demonstrated an association between the severities of necroinflammatory activity (including interface hepatitis as a major component) in an initial biopsy and the development of fibrosis or cirrhosis in follow up biopsies (9).

Bursts of lobular inflammatory activity are thought to be particularly important in pathogenesis of chronic hepatitis $C$ infection, where progression to cirrhosis is common despite the lack of interface activity (10). For these reasons it has been suggested that the pattern and severity of lobular inflammation should be taken in account in assessing the outcome in cases of chronic hepatitis (11).

\subsection{Assessment of hepatic fibrosis}

In the majority of cases fibrosis begins as expansion of portal tracts occurring in association of interface hepatitis. As fibrosis progresses, there is formation of septa with the development of portal-portal linkage. Eventually hepatocyte nodules are completely surrounded by fibrous tissue. Development of established cirrhosis usually takes several years. However, in some situations (e.g. viral hepatitis recurring following liver transplantation) cirrhosis can develop much more quickly. Parenchymal fibrosis can also occur in presence of lobular inflammation, particularly in areas of bridging necrosis (12). This may be responsible of for formation of portal-central septa, which have been regarded as more significant in the development of cirrhosis than portal-portal linkages (13).

\section{Historical perspectives: The terminology of chronic hepatitis}

The work of the two decades preceding the Knodell HAI provided the foundation for our current understanding of the histopathology of chronic hepatitis. Early descriptions and classifications focused on differentiating acute and chronic hepatitis and on lesions that predicted disease progression. The first histological classification, which was published by De Groote in 1968 (7), codified the terminology, chronic persistent and chronic aggressive hepatitis. Both conditions involved portal inflammation, but were distinguished by the severity of piecemeal necrosis, inflammation, and structural remodeling of the liver. Inflammatory activity was graded as moderate or severe, but exact criteria were not given. The classification system also incorporated the concept that chronic persistent hepatitis had a generally good prognosis whereas chronic aggressive hepatitis could evolve to cirrhosis (7).

Popper and Schaffner (1971) (14) affirmed the value of liver biopsy for diagnosis and prognosis and recommended use of "topographic" descriptors for hepatitis, that is, chronic lobular, chronic portal, or chronic periportal hepatitis. The last of these, synonymous with chronic aggressive hepatitis, was believed to progress, whereas chronic portal hepatitis, synonymous with chronic persistent hepatitis, was considered a non-progressive process. Chronic lobular hepatitis was a term for histological findings similar to those of acute hepatitis, but with a clinical duration of more than 3 months. It was thought to be nonprogressive except when seen in combination with chronic periportal hepatitis.

The explosion of scientific information on viral and non-viral hepatitis in the last decades of the 20th century led pathologists to question the conventional nomenclature of chronic 
persistent and chronic active (aggressive) hepatitis because of a growing understanding that etiology may be more significant than morphological classification in predicting the natural history of liver disease. This shift in thinking was driven largely by the apparent dissociation between the mild histology of non A-non B hepatitis (hepatitis C) and its progressive clinical course. It was found that, in many cases, the lesions of this form of viral hepatitis fell between those described as chronic persistent and chronic active hepatitis and could not be clearly categorized (15).

The lack of severe piecemeal necrosis and confluent lobular necrosis resulted in the diagnosis of chronic persistent hepatitis, implying a benign course. At the same time, the lobular component was being recognized as more significant than portal lesions with respect to disease progression. Also, confluent necrosis, which when present in severe autoimmune hepatitis and hepatitis B confers an ominous prognosis, is uncommon in hepatitis $\mathrm{C}$, and yet progression to fibrosis or cirrhosis occurs in all 3 diseases (2).

\section{Scoring systems currently in use}

For a system to be effective in every day diagnostic practice, it must be simple to understand, simple to apply, communicate effectively to the treating clinician, and clinically relevant (16). The system that is most appropriate for clinical practice may not be the most informative for investigative work (17).

\section{Histological grading and staging of chronic hepatitis (1) (Table 1)}

This scheme represents an extension of the original Knodell system, with a number of minor modifications. Firstly, a continuous scale is used for scoring each of the features assessed. Secondly, necroinflammatory activity and fibrosis are considered as separate categories. Thirdly, confluent necrosis is separated from periportal hepatitis and is included as a separate category of necroinflammatory activity. The term interface hepatitis was used in place of "piecemeal necrosis," to reflect the growing evidence that apoptosis, not necrosis, occurs at the limiting plate.

The first category (piecemeal necrosis) scores are defined as follows: 0, no piecemeal necrosis; 1 , focal piecemeal necrosis in few portal areas; 2, focal piecemeal necrosis in most portal areas; 3 , continuous piecemeal necrosis around $<50 \%$ of tracts or septa; 4 , continuous piecemeal necrosis around $>50 \%$ of tracts or septa.

The second category (Confluent Necrosis) scores are defined as follows: 0, no confluent necrosis; 1, focal confluent necrosis; 2, zone 3 necrosis in some areas; 3 , zone 3 necrosis in most areas; 4, zone 3 necrosis and occasional portal-central (P-C) bridging; 5 , zone 3 necrosis and multiple (P-C) bridging; 6, panacinar or multiacinar necrosis.

The third category (focal lytic necrosis, apoptosis, and focal inflammation) scores are defined as follows: 0 , No focal necrosis; 1 , one focus or less per 10x objective; 2 , two to four foci per $10 x$ objective; 3 , five to ten foci per $10 x$ objective; 4 , more than ten foci per $10 x$ objective.

The fourth category (portal inflammation) scores are defined as follows: 0, no portal inflammation; 1, mild in some or all portal areas; 2, moderate in some or all portal areas; 3, moderate to marked, all portal areas; 4 , marked in all portal areas. By combining scores for each of the four individual necroinflammatory categories, histological grading scores ranging from 0-18 can now be achieved. The overall activity scores are defined as follows: 13, minimal; 4-8, mild; 9-12, moderate; 13-18, severe (1). 
Ishak versus METAVIR:

\begin{tabular}{|c|c|c|c|c|c|c|c|}
\hline \multicolumn{8}{|c|}{ Modified HAI Grading: Necroinflammatory Scores } \\
\hline $\begin{array}{l}\text { Periportal or } \\
\text { Periseptal Interface } \\
\text { Hepatitis } \\
\text { (piecemeal necrosis) } \\
\text { (A) }\end{array}$ & Score & $\begin{array}{l}\text { Confluent } \\
\text { Necrosis } \\
\text { (B) }\end{array}$ & Score & $\begin{array}{l}\text { Focal (spotty) Lytic } \\
\text { Necrosis, Apoptosis, } \\
\text { and Focal } \\
\text { Inflammation* } \\
\text { (C) }\end{array}$ & Score & $\begin{array}{l}\text { Portal Inflammation } \\
\text { (D) }\end{array}$ & Score \\
\hline Absent & 0 & Absent & 0 & Absent & 0 & None & 0 \\
\hline $\begin{array}{l}\text { Mild (focal, few } \\
\text { portal areas) }\end{array}$ & 1 & $\begin{array}{l}\text { Focal confluent } \\
\text { necrosis }\end{array}$ & 1 & $\begin{array}{l}\text { One focus or less per } \\
\text { 10x objective }\end{array}$ & 1 & $\begin{array}{l}\text { Mild, some or all } \\
\text { portal areas }\end{array}$ & 1 \\
\hline $\begin{array}{l}\text { Mild/moderate } \\
\text { (focal, most portal } \\
\text { areas) }\end{array}$ & 2 & $\begin{array}{l}\text { Zone } 3 \text { necrosis } \\
\text { in some areas }\end{array}$ & 2 & $\begin{array}{l}\text { Two to four foci per } \\
\text { 10x objective }\end{array}$ & 2 & $\begin{array}{l}\text { Moderate, some or all } \\
\text { portal areas }\end{array}$ & 2 \\
\hline $\begin{array}{l}\text { Moderate } \\
\text { (continuous around } \\
<50 \% \text { of tracts or } \\
\text { septa) }\end{array}$ & 3 & $\begin{array}{l}\text { Zone } 3 \text { necrosis } \\
\text { in most areas }\end{array}$ & 3 & $\begin{array}{l}\text { Five to ten foci per } \\
\text { 10x objective }\end{array}$ & 3 & $\begin{array}{l}\text { Moderate/marked, all } \\
\text { portal areas }\end{array}$ & 3 \\
\hline $\begin{array}{l}\text { Severe (continuous } \\
\text { around }>50 \% \text { of } \\
\text { tracts or septa) }\end{array}$ & 4 & $\begin{array}{l}\text { Zone } 3 \text { necrosis } \\
+ \text { occasional } \\
\text { portal-central } \\
(\mathrm{P}-\mathrm{C}) \text { bridging }\end{array}$ & 4 & $\begin{array}{l}\text { More than ten foci } \\
\text { per } 10 x \text { objective }\end{array}$ & 4 & $\begin{array}{l}\text { Marked, all portal } \\
\text { areas }\end{array}$ & 4 \\
\hline & & $\begin{array}{l}\text { Zone } 3 \text { necrosis } \\
+ \text { multiple P-C } \\
\text { bridging }\end{array}$ & 5 & & & & \\
\hline & & \begin{tabular}{|l} 
Panacinar or \\
multiacinar \\
necrosis
\end{tabular} & 6 & & & & \\
\hline
\end{tabular}

\begin{tabular}{|l|l|}
\hline Modified Staging: architectural changes, fibrosis and cirrhosis & \\
\hline Change & Score \\
\hline No fibrosis & $\mathbf{0}$ \\
\hline Fibrous expansion of some portal areas, with or without short fibrous septa & 1 \\
\hline Fibrous expansion of most portal areas, with or without short fibrous septa & 2 \\
\hline Fibrous expansion of most portal areas with occasional portal to portal (P-P) bridging & 3 \\
\hline $\begin{array}{l}\text { Fibrous expansion of portal areas with marked bridging [portal to portal (P-P) as well as } \\
\text { portal to central (P-C)] }\end{array}$ & 4 \\
\hline Marked bridging (P-P and/or P-C) with occasional nodules (incomplete cirrhosis) & 5 \\
\hline Cirrhosis, probable or definite & $\mathbf{6}$ \\
\hline
\end{tabular}

Additional features that should be noted but not scored: bile-duct inflammation and damage; lymphoid follicles; steatosis, mild, moderate, or marked; hepatocellular dysplasia, large- or small-cell; adenomatous hyperplasia; iron or copper overload; intracellular inclusions (e.g. PAS-positive globules, Mallory bodies); and immunohistochemical findings. Information on viral antigens, lymphocyte subsets, or other features, when available, should be recorded and may be semi-quantitatively expressed.

Modified and reprinted (1).

Table 1. Ishak Modified HAI (1995) (1).

The fibrosis scores are defined as follows: 0 , no fibrosis; 1 , fibrous expansion of some portal areas, with or without short fibrous septa; 2, fibrous expansion of most portal areas, with or without short fibrous septa; 3, fibrous expansion of most portal areas with occasional portal to portal bridging; 4, fibrous expansion of most portal areas with marked bridging (portal to 
portal as well as portal to central); 5 , marked bridging with occasional nodules (incomplete cirrhosis); 6, cirrhosis, probable or definite (1).

Difficulties with the Ishak system have been noted. Use of the X10 objective for the evaluation of necroinflammatory foci raises concerns of reproducibility, because the size of the field may vary among microscopes. In addition, definitions of a "focus" of lymphocytic aggregates, apoptotic hepatocytes, or confluent necrosis may vary among pathologists (18).

\section{Algorithm for the grading of activity in chronic hepatitis (METAVIR system) (Table 2)}

The French METAVIR Cooperative Study Group stated that another possible approach for grading the necroinflammatory activity is to consider that periportal and intra-lobular necroinflammatory lesions are related to the same pathologic mechanism and that they must be globally assessed. A panel decided to define activity according to its potential predictive value for the occurrence of liver fibrosis. They chose to include in algorithm only two features (piecemeal necrosis and lobular necrosis) (19).

Portal inflammation was excluded from the algorithm, because this feature is a prerequisite for the definition of chronic hepatitis even without activity. Furthermore they observed a strong correlation with piecemeal necrosis, making these two features redundant criteria.

Piecemeal necrosis was chosen as the first decision criterion because of its proven potential value in other types of chronic hepatitis. It was then suspected that another feature, lobular necrosis, was of major importance in the prediction of liver fibrosis. It is believed that aggravation of chronic hepatitis $\mathrm{C}$ occurs through a burst of lobular necrosis, a lesion that is frequently present in chronic hepatitis $\mathrm{C}$. The two lesions were therefore combined to propose a simple algorithm that defined activity.

In several existing classifications, the degree of piecemeal and lobular necrosis was independently assessed and their scores then added, thus giving each of these two lesions the same weight in the definition of activity. The METAVIR system included both piecemeal necrosis and lobular necrosis in the definition of activity, but with different values. The rationale for overweighting the piecemeal necrosis item by comparison with lobular necrosis is that piecemeal necrosis is the major discriminating factor used to grade activity, as shown by stepwise discriminate analysis.

The first criterion (piecemeal necrosis) scores are defined as follows: 0, absent; 1, focal alteration of the periportal plate in some portal tracts; 2 , diffuse alteration of the periportal plate in some portal tracts or focal lesion around all portal tracts; 3 , diffuse alteration of the periportal plate in all portal tracts.

The second criterion (focal lobular necrosis) scores are defined as follows: 0, less than one necroinflammatory foci per lobule; 1 , at least one necroinflammatory foci per lobule; 2 , several necroinflammatory foci per lobule or confluent or bridging necrosis. The overall activity scores are defined as follows: 0 , No activity; 1 , mild; 2 , moderate; 3 , severe (20).

The fibrosis scores are defined as follows: F0, no fibrosis; F1, portal fibrosis without septa; F2, portal fibrosis with rare septa; F3 numerous septa without cirrhosis; F4, cirrhosis (19).

The METAVIR system has the advantage of simplicity, reproducibility and application to a large number of biopsies (20). This score is composed of a two-letter and two-number coding system: $\mathrm{A}=$ histological activity and $\mathrm{F}=$ fibrosis (Table 2 ). 


\section{Algorithm for evaluation of histological activity}

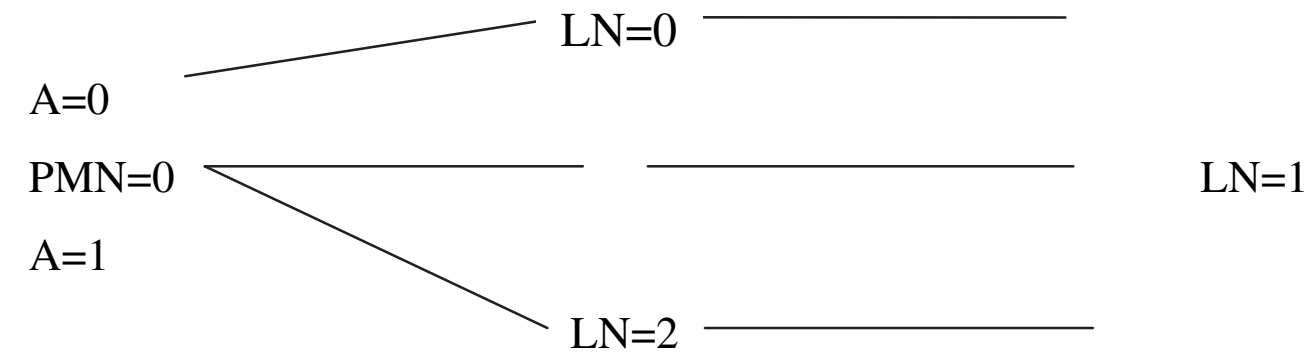

$\mathrm{A}=2$

$\mathrm{PNN}=1$

$\mathrm{A}=1$

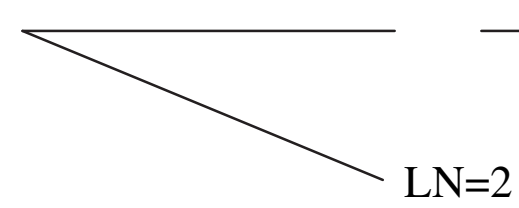

$\mathrm{LN}=0,1$

$\mathrm{A}=2$

$A=2$

$\mathrm{PMN}=2$

$\mathrm{LN}=2$

$\mathrm{PMN}=3$

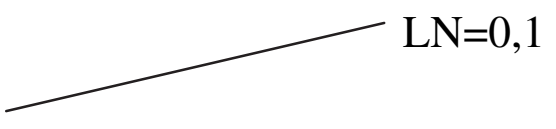

$\mathrm{A}=3$

PMN, piecemeal necrosis; 0, none; 1 , mild; 2, moderate; 3, severe; LN, lobular necrosis; 0, no or mild; 1 , moderate; 2 , severe; A, histological activity; 0 , none; 1 , mild; 2 , moderate; 3 , severe.

\begin{tabular}{|l|l|}
\hline Fibrosis Scoring \\
\hline Score & Description \\
\hline 0 & No fibrosis \\
\hline 1 & Stellate enlargement of portal tract but without septa formation \\
\hline 2 & Enlargement of portal tract with rare septa formation \\
\hline 3 & Numerous septa formation \\
\hline 4 & Cirrhosis \\
\hline
\end{tabular}

Modified and reprinted (20).

Table 2. The METAVIR System. 


\section{Problems with histological scoring}

There are a number of problems which apply to all the scoring systems currently in use.

- Lack of scientific validation:

A fundamental problem with histological "scoring" is that the numbers which are generated do not represent measurement of continuous variable. Instead, they simply represent different categories of severity. This contrasts with biochemical measurements, for example, serum transaminases, for which a true numerical progression can be more readily justified (21).

- Observer variation:

There are problems in obtaining reproducible results, even when scoring system is applied by experts in the field of liver pathology. In general, better reproducibility has been obtained for scoring fibrosis than for scoring inflammatory activity. This is probably due to imprecise terminology which is used in individual histological features. Terms such as "occasional", "some", or "mild", "moderate and "severe" are used without defining precisely what these mean (22).

- Sampling Variation:

Much of the knowledge regarding this problem has come from the examination of hepatectomy specimens obtained at liver transplantation. Sampling variation exist, both for the grade of necroinflammatory activity and for the stage of fibrosis. For example, small areas of multiacinar necrosis can often be found in a liver which otherwise show a relatively inactive cirrhosis. These areas are typically subcapsular in location but may be also present elsewhere. If a needle biopsy is taken from one of these areas, a "falsely high" inflammatory score may be obtained. Chronic viral hepatitis may affect the liver uniformly, but considerable variation in the severity of fibrosis can be seen when whole liver are available for examination (2).

- Etiological considerations:

The scoring systems currently in common use incorporate histological features which may be seen in all types of chronic hepatitis. However, different types of chronic hepatitis have marked differences in natural history and response to therapy. These differences in behavior may be reflected by different patterns of histological damage. For example, ballooning, rosetting, and giant cell transformation may be regarded as signs of severe damage in cases of autoimmune hepatitis, even in the absence of conspicuous inflammatory activity. Direct cytopathic damage (e.g. ballooning or fatty change) may be important in the pathogenesis of fibrosis in chronic hepatitis $C$ infection (2).

\section{Terminology in METAVIR}

Terminology in METAVIR as regard fibrosis stage assessment is not clear and confusing; with narrow range (F0-F4). F3 indicates numerous septa, however, in practical application early (developing) cirrhosis is included too, irrespective of being not described in the score details. On the other hand, Ishak fibrosis score is wider (0-6), more sensitive, as well clearly separate incomplete (developing, early) cirrhosis from established cirrhosis $(\mathbf{1}, \mathbf{2 0}, \mathbf{2 3})$.

Rozario and Ramakrishna, 2003(24) have built their analysis, tables and comparison on the inaccurate idea that F2 of METAVIR (rare septa) is equal to stage 2 of Ishak. However, the correct is that, F1 stage of METAVIR is equal to stages $1 \& 2$ of Ishak, and F2 of METAVIR is equal to stage 3 of Ishak (occasional bridging fibrosis). This resulted in a defect that may affect the idea and the conclusion (4). 
Applying semi-quantitative terminology reflecting grades of necroinflammatory injury as recorded by Ishak may underestimate the severity of these changes. In Ishak scoring, 6 points out of the 18 are related to confluent necrosis, which is a rare event in chronic hepatitis C.

Elzbieta and Marek, 2005 (25) reported that, the comparison of three histological scoring systems used to evaluate chronic hepatitis (Batts and Ludwig, Ishak et al. and METAVIR scoring systems) revealed a high coefficient of positive correlation between the respective scales. Thus, the systems seem comparable in the estimation of the inflammation grade and stage of fibrosis. Table 2 may be advised for converting fibrosis score from Ishak to METAVIR.

Goodman in his review 2007(26), considered Ishak stage 5 (incomplete cirrhosis) to be included in METAVIR F4 stage, that is different from the opinion of Bedossa and others of METAVIR group. This is a pitfall that may affect the results of some research studies.

\section{Current applications of Ishak and METAVIR scoring systems}

In assessment of regression of fibrosis after autoimmune hepatitis treatment, Abdalla et al, 2009 have reported higher sensitivity of Ishak compared with METAVIR in detection of fibrosis regression (27). They also found statistically higher sensitivity for quantitative assessment of fibrosis by analysis of digitalized pictures of sirus red. Czaja and Carpente 2004, reported a sensitivity of Ishak in assessment of fibrosis regression (28). Esmat et al, 2007 (applying Ishak fibrosis score) have demonstrated a correlation between fibrosis score and hyaluronic acid level (29). Tsochatzis1 et al 2011, in their meta-analysis of diagnostic accuracy of elastography for the diagnosis of severity of fibrosis in chronic liver disease, the different stages of fibrosis (scoring systems) were converted to comparable stages in METAVIR (30). Goodman 2007, suggested application of METAVIR in routine work, and Ishak score in clinical trials, because of higher sensitivity in fibrosis assessment (28). Lefkowitch 2007 and Guido et al, 2011, suggested application of any of the scoring systems, that is not home made, and the clinicians with whom they work prefer $(31,32)$.

Although liver biopsy has long been regarded as a gold standard procedure, it has obvious limitations. It represents an approximation of liver fibrosis for the whole liver and is, therefore, not the gold standard for fibrosis assessment. Nevertheless, it is the best procedure currently available (33). Germani et al 2010 recommend liver pathologists to perform computer-assisted digital analysis of Sirius red-stained histological sections in addition to the scoring system established to describe the stage of the liver disease (34).

\section{Conclusions}

Regarding fibrosis:

- Ishak and METAVIR are nearly identical; however, Ishak is of a wider scale.

- The term "Septa" in METAVIR is equal to "bridging fibrosis" in Ishak.

- $\quad$ F3 stage in METAVIR score includes incomplete (developing) cirrhosis.

Regarding necroinflammatory injury

- METAVIR is more sensitive to severe activity and more reproducible. However, without numerical scoring that let it less effective for monitoring minor changes.

- Ishak modified HAI has a wider scale. However, 6 points of it (confluent necrosis) are nearly out of the chronic hepatitis $C$ scope. This minimizes the actual scoring to 12 points instead of 18 in practical application. 
- $\quad$ The proposed table is advised for unidirectional converting fibrosis scores from Ishak to METAVIR.

- $\quad$ METAVIR F3 stage may better be subdivided into F3a: Marked bridging fibrosis and F3b: incomplete (early cirrhosis) (developing cirrhosis).

More work is needed in:

- Assessing the validity of the current scoring systems in post-liver transplant patients with recurrent $\mathrm{HCV}$ especially those with a back ground of graft pathologies such as rejection and those with associated HBV or cytomegalovirus and HIV infections.

- Convertibility of the results of these scoring systems and image pattern of contrast enhanced ultrasound of the liver.
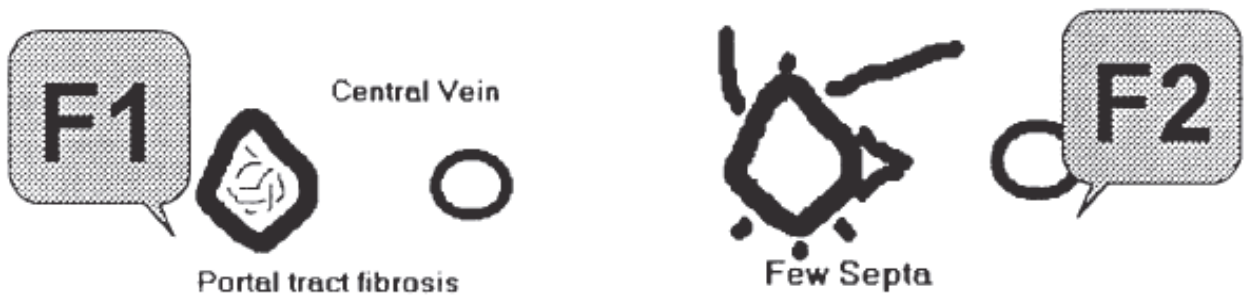

Few Septa
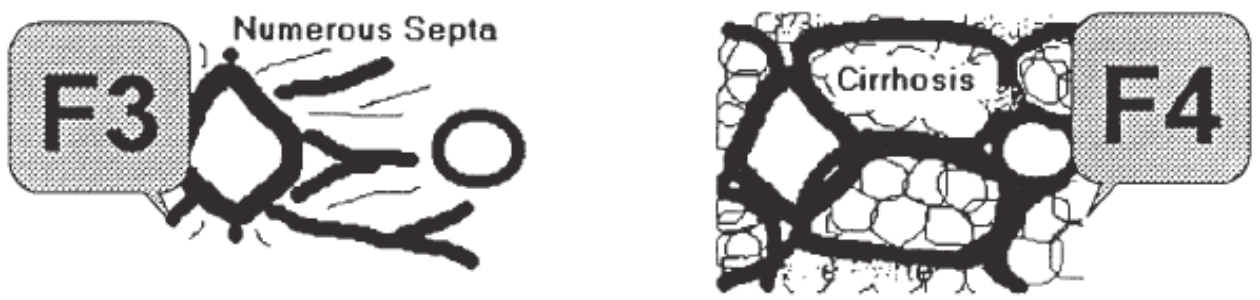

Modified and reprinted (19).

\begin{tabular}{|l|l|}
\hline Ishak, 1995. & METAVIR Score. \\
Fibrosis: $\mathbf{0 - 6}$ & Fibrosis: F 0-4 \\
0 & 0 \\
$1-2$ & 1 \\
3 & 2 \\
$4-5$ & 3 \\
6 & 4 \\
\hline
\end{tabular}

Fig. 1. The METAVIR Fibrosis staging system. F0 is normal liver (no fibrosis). $\mathrm{F} 1=$ portal fibrosis. $\mathrm{F} 2$ = few septa. $\mathrm{F} 3=$ many septa. $\mathrm{F} 4=$ cirrhosis. 
Ishak versus METAVIR:

Terminology, Convertibility and Correlation with Laboratory Changes in Chronic Hepatitis C

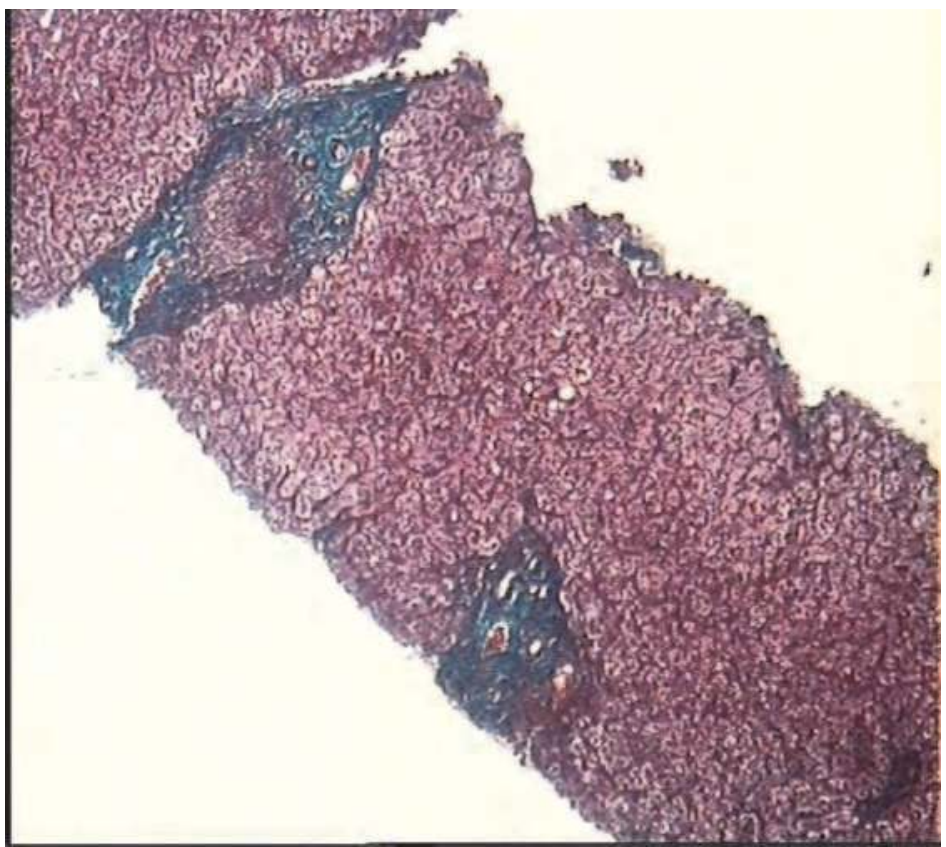

Fig. 2. Portal tract expansion by fibrosis, Masson trichrom stain.

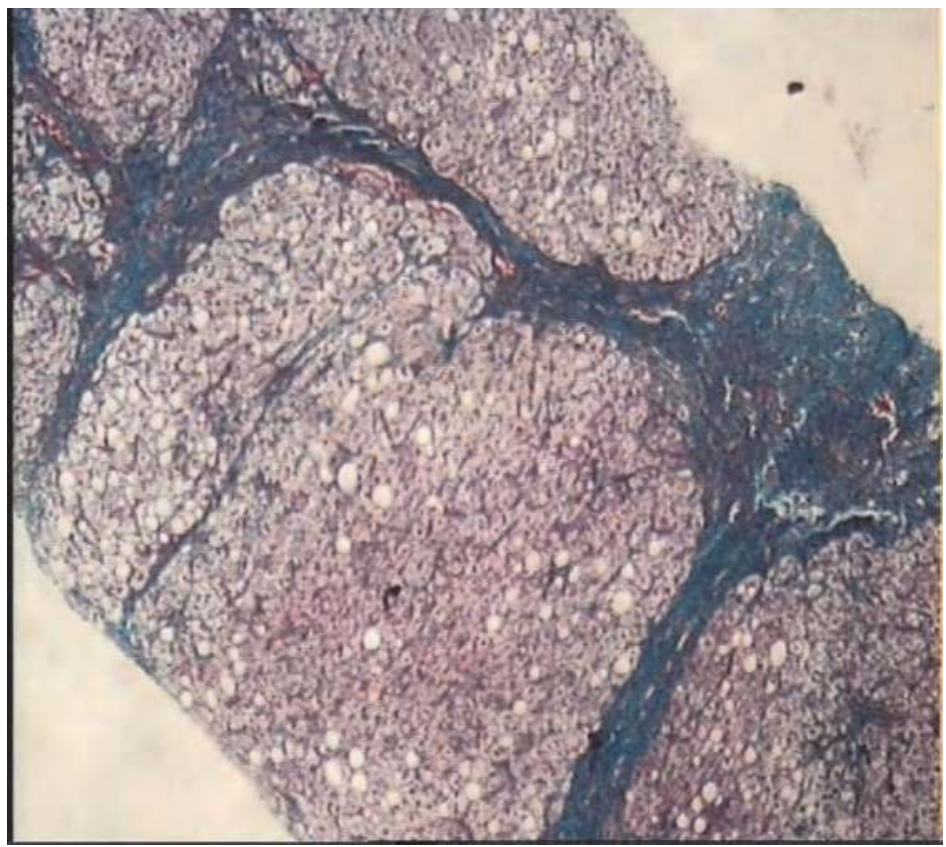

Fig. 3. Bridging fibrosis, Masson trichrom stain. 


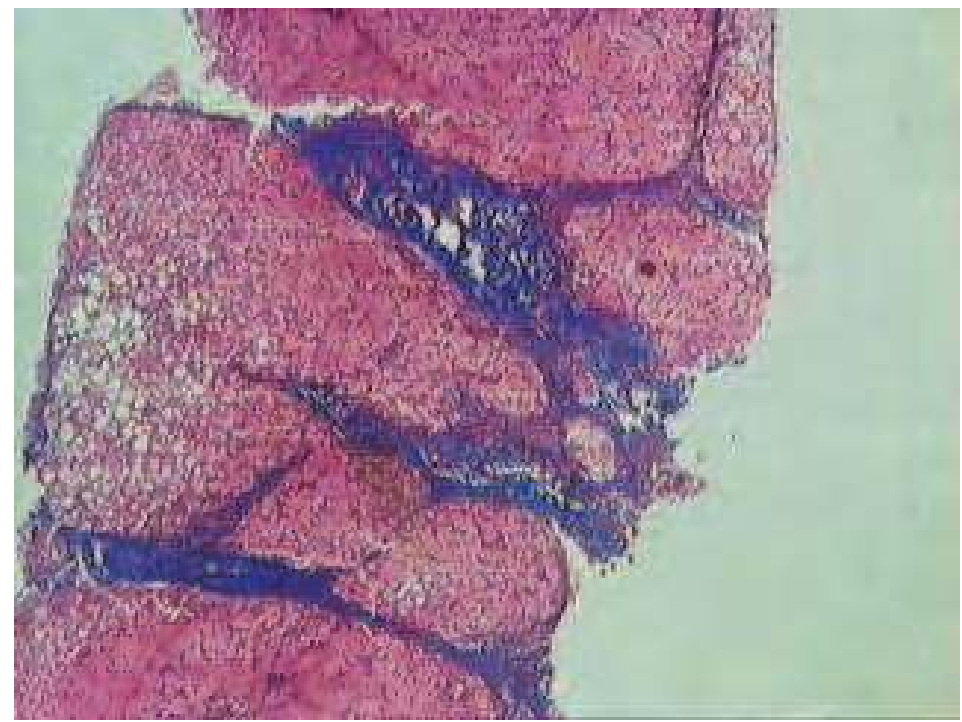

Fig. 4. Multiple portal-portal bridges, , Masson trichrom stain.

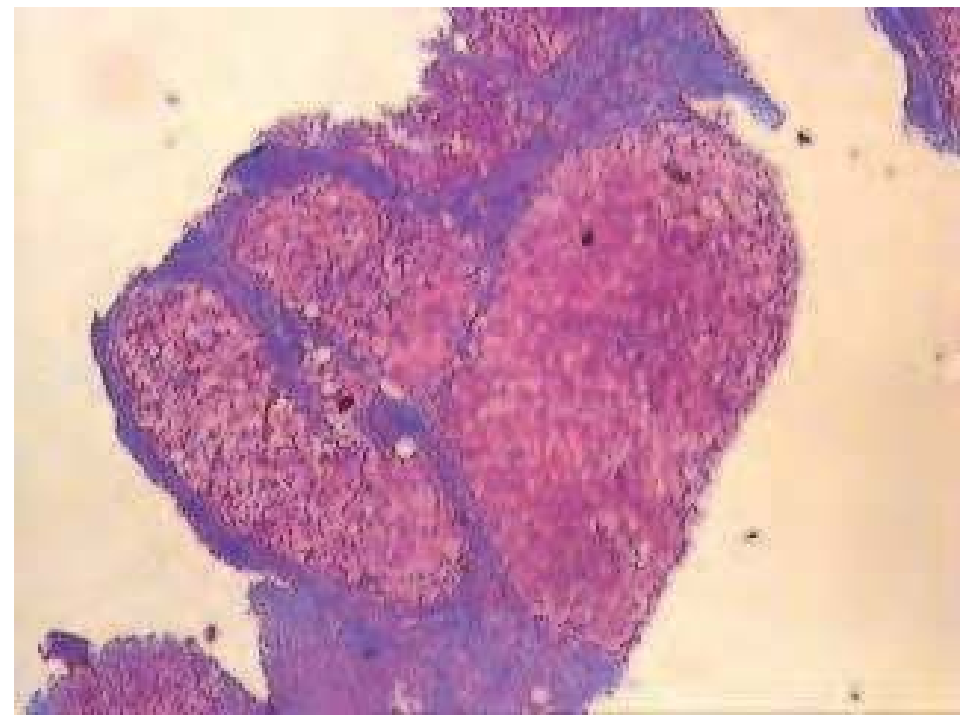

Fig. 5. Regenerating nodules rimmed by fibrosis, Masson trichrom stain. 
Ishak versus METAVIR:

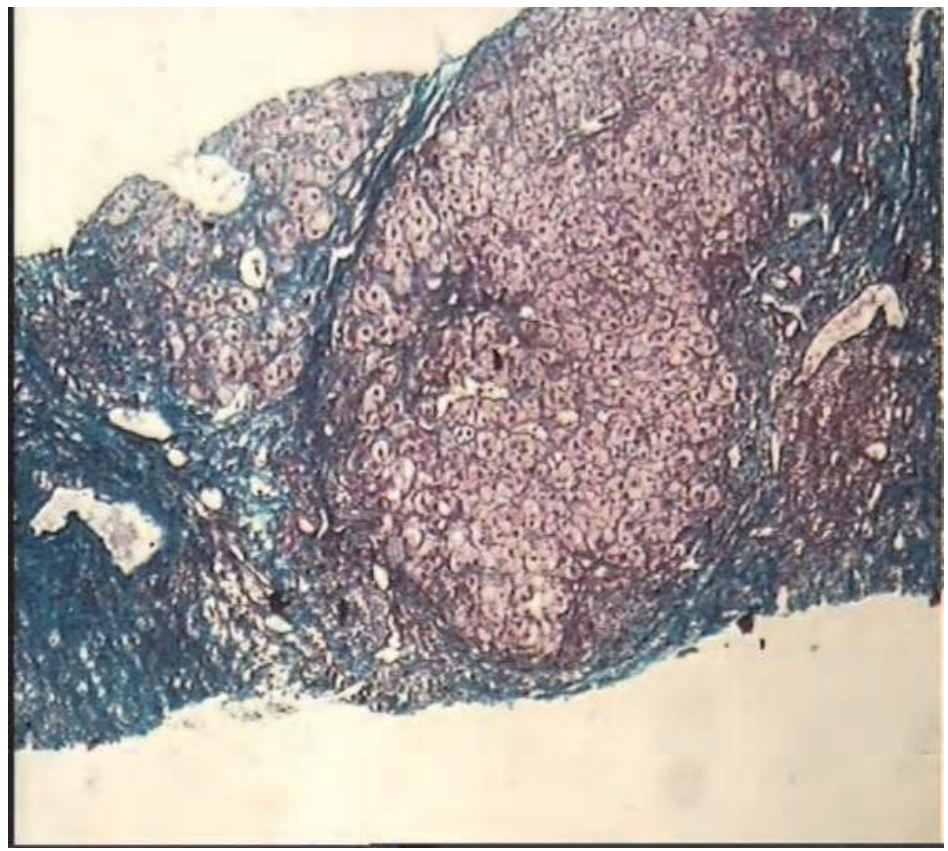

Fig. 6. Regenerating nodules rimmed by dense fibrosis, Masson trichrom stain.

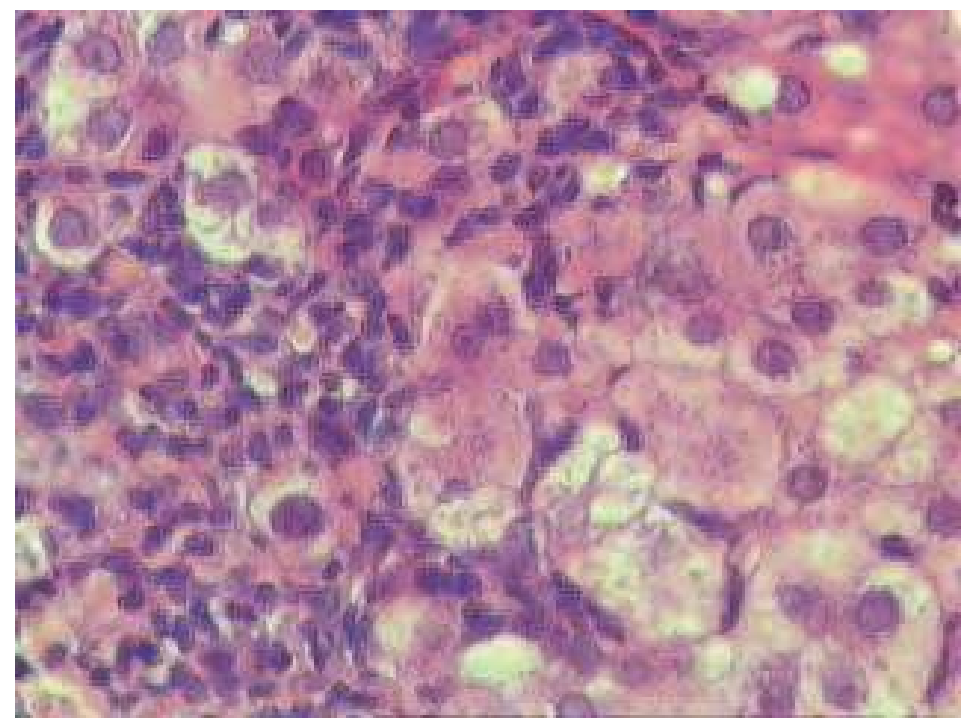

Fig. 7. Interface hepatitis, H\&E stain. 


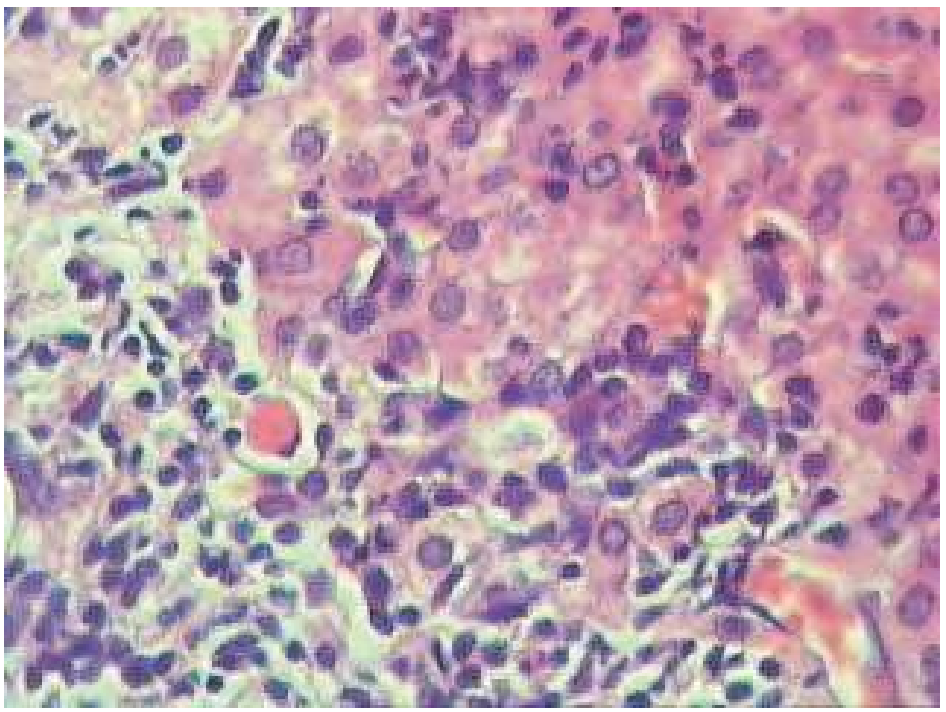

Fig. 8. Evident interface hepatitis with apoptosis, H\&E stain.

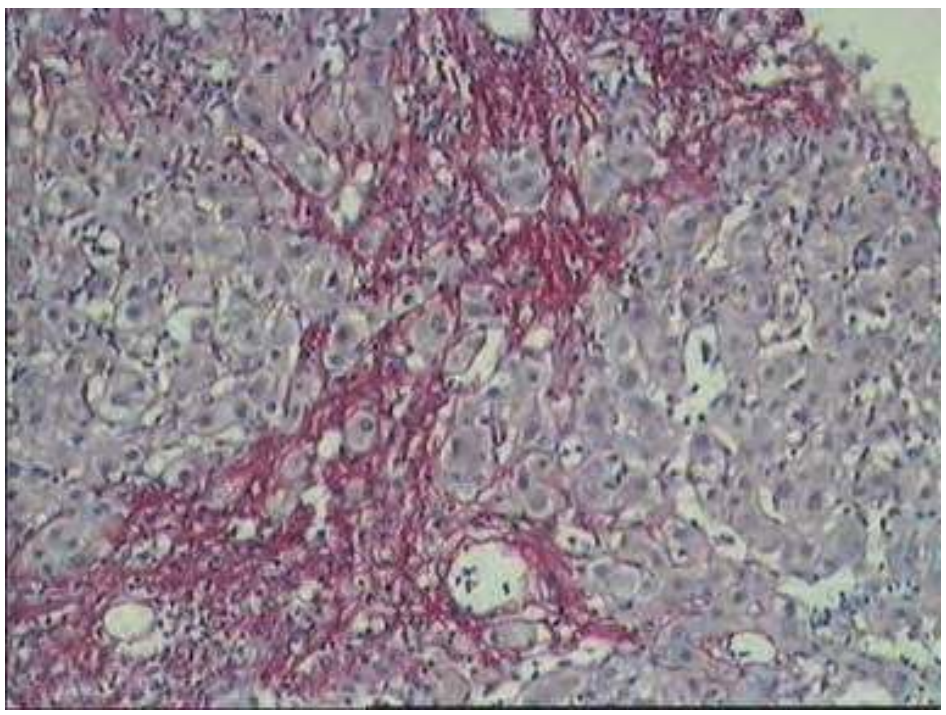

Fig. 9. Confluent necrosis, reticulin collapse , sirus red stain.

\section{References}

[1] Ishak K, Baptista A, Bianchi L, et al. Histologic grading and staging of chronic hepatitis. J Hepatol 1995;24:289-293. 
[2] Hübscher S. Histological grading and staging in chronic hepatitis: clinical applications and problems. J Hepatol 1998;29:1015-1022.

[3] Salmi M, Adams D, Jalkanen S. Cell adhesion and migration. IV Lymphocyte trafficking in the intestine and liver. Am J Physiol 1998;274:1-6.

[4] Kay FW, O'Dowd J, Thomas R, et al. Mild abnormalities in liver histology associated with chronic hepatitis: distinction from normal liver histology. J Clin Pathol 1997;50:929-931.

[5] Galle P. Apoptosis in liver disease. J Heptol 1997;27:405-412.

[6] MacSween R, Desmit V, Roskams T, et al. Developmental anatomy and normal structure in: MacSween R, Burt A, Portman B, Ishak K, Scheuer P, and Anthony P (eds): Pathology of the liver. $4^{\text {th }}$ edition (2002), Churchill, Livingston, PP: 1-66.

[7] De Groote J, Desmet VJ, Gedigk P, et al. A classification of chronic hepatitis. Lancet 1968;2:626-628.

[8] Mattson L, Weiland O, Glaumann H. Application of numerical scoring system for assessment of histological outcome in patient with chronic post transfusion non-A, non-B hepatitis with or without antibody to hepatitis C. Liver 1990;10:257-263.

[9] Poynard T, Bedossa P, Opolon P. Natural history of liver fibrosis progression in patients with chronic hepatitis C. Lancet 1997;349:825-832.

[10] Lefkwitch J, Schiff E, Davis G, et al. Pathological diagnosis of chronic hepatitis C: a multicenter comparative study with chronic hepatitis B. Gastroenterology 1993;104:595-603.

[11] Popper H. Changing concepts of the evolution of chronic hepatitis and the role of piecemeal necrosis. Hepatology 1983;5:758-762.

[12] Cooksley W, Bradbear R, Robinson W, et al. The prognosis of chronic active hepatitis without cirrhosis in relation to bridging necrosis. Hepatology 1986;6:345-348.

[13] Desmet V, Gerber M, Hoofnagle J, et al. Classification of chronic hepatitis: diagnosis, grading and staging. Hepatology 1994;19:1513-1520.

[14] Popper H, Schaffner F. The vocabulary of chronic hepatitis. N Engl J Med 1971;284:1154-1156.

[15] Scheuer P. Chronic hepatitis: what is activity and how should it be assessed? Histopathology 1997;30:103-105.

[16] Okafor O, Ojo S. A comparative analysis of six current histological classification schemes and scoring systems used in chronic hepatitis reporting. Rev Esp Pathol 2004;37:269-277.

[17] Brunt E. Grading and staging the histopathological lesions of chronic hepatitis: the Knodell histology activity index and beyond. Hepatology 2000;31:241-246.

[18] Westin J, Lagging LM, Wejstal R, et al. Interobserver study of liver histopathology using the Ishak score in patients with chronic hepatitis $\mathrm{C}$ virus infection. Liver 1999;19:183-187.

[19] Poynard T Ratziu V, Benmanov Y, et al. Fibrosis in patients with chronic hepatitis C: detection and significance. Semin Liv Dis 2000;20:47-55.

[20] Bedossa P, Poynard T and the French METAVIR Cooperative Study Group. An algorithm for grading activity in chronic hepatitis C. Hepatology 1996;24:289-293.

[21] Scheuer P. Classification of chronic viral hepatitis: a need for reassessment. J Hepatol 1991;13:372-374. 
[22] Golden R, Golden J, Burt A, et al. Intra-observer and inter-observer variation in the histopathological assessment of chronic viral hepatitis. J Hepatol 1996;25:649-654.

[23] Bedossa P, Callard P, Degott C, et al. Intraobserver and interobserver variations in liver biopsy interpretation in patients with chronic hepatitis C. Hepatology 1994;20:1520.

[24] Rozario and Ramakrishna. Histopathological study of chronic hepatitis B and C: a comparison of two scoring systems. J Hepatol 2003;38:223-229.

[25] Maria Elzbieta SL, Marek LD. Histological outcome of chronic hepatitis B in children treated with interferon alpha. World J Gastroenterol 2005;11:7179-7182.

[26] Goodman ZD. Grading and staging systems for inflammation and fibrosis in chronic liver diseases. J Hepatol 2007;47:598-607.

[27] Abdalla AF, Zalata KR, Ismail AF, et al. Regression of fibrosis in pediatric autoimmune hepatitis: morphometric assessment of fibrosis versus semiquantiatative methods. Fibrogenesis Tissue Repair 2009;2:2.

[28] Czaja AJ, Carpenter HA. Autoimmune hepatitis with incidental histologic features of bile duct injury. Hepatology 2001;34:659-665.

[29] Esmat G, Metwally M, Zalata KR, et al., Evaluation of serum biomarkers of fibrosis and injury in Egyptian patients with chronic hepatitis C. J Hepatol 2007;46:620-627.

[30] Tsochatzis EA, Gurusamy KS, Ntaoula S. Elastography for the diagnosis of severity of fibrosis in chronic liver disease: A meta-analysis of diagnostic accuracy. J Hepatol 201;54:650-659.

[31] Lefkowitch JH. Liver biopsy assessment in chronic hepatitis. Arch Med Res 2007;38:634-643.

[32] Guido M, Mangia A, Faa G. Chronic viral hepatitis: the histology report. Dig Liver Dis 2011;43(Suppl 4):S331-343.

[33] Bedossa P. Liver biopsy. Gastroenterol Clin Biol 2008;32(6 Suppl 1):4-7.

[34] Germani G, Burroughs AK, Dhillon AP. The relationship between liver disease stage and liver fibrosis: a tangled web. Histopathology Histopathology 2010;57:773-784. 


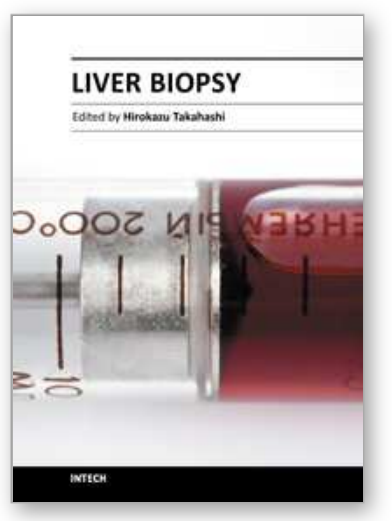

\author{
Liver Biopsy \\ Edited by Dr Hirokazu Takahashi
}

ISBN 978-953-307-644-7

Hard cover, 404 pages

Publisher InTech

Published online 06, September, 2011

Published in print edition September, 2011

Liver biopsy is recommended as the gold standard method to determine diagnosis, fibrosis staging, prognosis and therapeutic indications in patients with chronic liver disease. However, liver biopsy is an invasive procedure with a risk of complications which can be serious. This book provides the management of the complications in liver biopsy. Additionally, this book provides also the references for the new technology of liver biopsy including the non-invasive elastography, imaging methods and blood panels which could be the alternatives to liver biopsy. The non-invasive methods, especially the elastography, which is the new procedure in hot topics, which were frequently reported in these years. In this book, the professionals of elastography show the mechanism, availability and how to use this technology in a clinical field of elastography. The comprehension of elastography could be a great help for better dealing and for understanding of liver biopsy.

\title{
How to reference
}

In order to correctly reference this scholarly work, feel free to copy and paste the following:

Gamal Shiha and Khaled Zalata (2011). Ishak versus METAVIR: Terminology, Convertibility and Correlation with Laboratory Changes in Chronic Hepatitis C, Liver Biopsy, Dr Hirokazu Takahashi (Ed.), ISBN: 978-953307-644-7, InTech, Available from: http://www.intechopen.com/books/liver-biopsy/ishak-versus-metavirterminology-convertibility-and-correlation-with-laboratory-changes-in-chronic-h

\section{INTECH}

open science | open minds

\section{InTech Europe}

University Campus STeP Ri

Slavka Krautzeka 83/A

51000 Rijeka, Croatia

Phone: +385 (51) 770447

Fax: +385 (51) 686166

www.intechopen.com

\section{InTech China}

Unit 405, Office Block, Hotel Equatorial Shanghai

No.65, Yan An Road (West), Shanghai, 200040, China 中国上海市延安西路65号上海国际贵都大饭店办公楼 405 单元

Phone: +86-21-62489820

Fax: $+86-21-62489821$ 
(C) 2011 The Author(s). Licensee IntechOpen. This chapter is distributed under the terms of the Creative Commons Attribution-NonCommercialShareAlike-3.0 License, which permits use, distribution and reproduction for non-commercial purposes, provided the original is properly cited and derivative works building on this content are distributed under the same license. 